Estudios Constitucionales, Año 8, No 2, 2010, pp. 167 - 200.

ISSN 0718-0195

Centro de Estudios Constitucionales de Chile Universidad de Talca

"Las limitaciones a los derechos fundamentales"

Hugo Tórtora Aravena

\title{
LAS LIMITACIONES A LOS DERECHOS FUNDAMENTALES
}

\author{
THE LIMITATIONS TO THE FUNDAMENTAL RIGHTS
}

\author{
Hugo Tórtora Aravena* \\ Profesor de Derecho Constitucional de la \\ Universidad Andrés Bello de Viña del Mar. \\ htortora@unab.cl
}

RESUMEN: En el presente trabajo, el autor aborda un tópico central dentro de la Dogmática de los Derechos Fundamentales, como son sus Limitaciones.

En él, se presenta un concepto de dichas limitaciones, para luego analizar diversas clasificaciones de las mismas, distinguiendo según criterios que tienen que ver con las circunstancias en las que operan, el origen de las limitaciones, y la norma en la que constan o se establecen.

Respecto de los requisitos que deben cumplir estas limitaciones para que sean legítimas, el autor se refiere a condiciones de carácter competencial, internacional, material y lógico.

Finalmente, el trabajo propone la existencia de lo que él denomina "limitaciones fácticas" de los derechos fundamentales, que estarian representadas por restricciones ilegitimas que son establecidas o toleradas por la institucionalidad estatal, en especial, por los Tribunales de Justicia, quienes, en sus sentencias, terminan reconociéndolas con fuerza de cosa juzgada.

ABSTRACT: In this work, the author discusses the Fundamental Rights Restrictions which are a main topic within the Dogmatics of the Fundamental Rights

Firstly, a concept of those restrictions is given. Then, different classifications are analyzed, using criteria related to the circumstances under which the restrictions are applied, the origin of the restrictions, and the norm where those limitations are stated or mentioned.

Regarding the requirements these restrictions must fulfill in order to be considered as legitimate, the author mentions competence, international, material, and logic conditions.

Finally, it is proposed the existence of what the author calls "factual restrictions" on the fundamental rights. These restrictions are represented by illegitimate restrictions on the rights, established or tolerated by the institutionality of the state. This is especially the case of the sentences imposed by the Courts of Law which recognize these restrictions with the authority of res judicata.

*El autor es abogado. Licenciado en Ciencias Jurídicas de la Universidad de Valparaíso, Magíster en Derecho Constitucional mención Derecho Procesal Constitucional por la Universidad de Talca, Docente de Jornada Completa en la Universidad Andrés Bello de Viña del Mar. Docente en las áreas de Derecho Político y Constitucional de las Universidades Andrés Bello y Santo Tomás, todas de Viña del Mar. Miembro inscrito de la Asociación Chilena de Derecho Constitucional y del Capítulo chileno del Ombudsman. El autor agradece los aportes y comentarios de los profesores Miguel Ángel Fernández y Paula Artus Poblete; sin embargo, los errores que pudieren existir en el trabajo son de responsabilidad de su autor. Correo electrónico: htortora@ unab.cl - hugotortora@gmail.com Recibido el 30 de abril de 2010, aprobado el 4 de agosto de 2010. 
PALABRAS CLAVE: Derechos Fundamentales. Limitaciones a los Derechos Fundamentales. Limitaciones Fácticas a los Derechos Fundamentales. Jurisdicción Constitucional.

KEY WORDS: Fundamental Rights. Fundamental Rights Restrictions. Factual Restrictions on the Rights. Constitutional Jurisdiction.

\section{Concepto de limitaciones de Derechos FUndamentales}

Los derechos fundamentales, si bien no deben ser condicionados en cuanto a su ejercicio, están sujetos a límites, explícitos o no. En palabras de José Luis Cea, estos derechos se tratan "de atributos que jamás tienen alcance absoluto, pues si lo poseyeran se convertirían en prerrogativas típicas de un déspota que obra, con rasgos ilícitos o abusivos".

Es así que el ejercicio de los derechos fundamentales se encuentra restringido por determinadas exigencias propias de la vida en sociedad. Ello no se contrapone a la convicción de entender que el Ser Humano ha de ser el centro de toda comunidad organizada, sino, muy por el contrario, se vincula con un reforzamiento de las garantías de una existencia plena, pacífica y respetuosa por los derechos y la dignidad humana.

Reconocer, por tanto, que los derechos están sujetos a limitaciones no significa restar a estas facultades del máximo valor y relevancia en el ordenamiento jurídico.

Se trata de un conjunto de atributos, cuyo respeto y protección son una de las claves más importantes para evaluar la verdadera legitimidad de un modelo político y social. Y ello, finalmente, por cuanto son derechos que cuentan no sólo con una naturaleza subjetiva, sino que también con una dimensión objetiva que excede a la mera titularidad radicada en una persona determinada y, especialmente, por su íntima ligazón con la más noble esencia del ser humano, como es su dignidad. Con esa misma carga valorativa, Jorge M. Quinzio nos recuerda: "Los Derechos Humanos no son para aprenderlos de memoria. Todo el catálogo de los Derechos Humanos es para mejorarlos y sacar conclusiones de cuando ellos fueron vulnerados, para nunca más vivirlo ni negarlos, para que todos tengan conocimiento de ellos, para hacerlos valer, respetarlos y exigir su respeto, vigencia y garantía y hacerlos aplicables".

No obstante lo anterior, y como hemos dicho, los Derechos Fundamentales no son absolutos ni ilimitados, sino que en verdad se encuentran sometidos a una serie de restricciones o limitaciones que provocan que su titular no pueda ejercer válidamente una determinada prerrogativa en ciertas circunstancias.

\footnotetext{
${ }^{1}$ CEA (2002), p. 58.

${ }^{2}$ Quinzio (2006), p. 44.
} 
Jaime Guzmán lo explicaba en sus cátedras: "Los derechos humanos no son absolutos, en el sentido de ilimitados. Desde el momento en que su titular es un ser contingente y no absoluto, limitado y no infinito, sus derechos están sujetos-forzosa e inevitablemente- a ciertos límites (...). Más allá de los límites que impone la moral en aquellos ámbitos que corresponden exclusivamente al juicio de Dios y de la propia conciencia, la vida en sociedad exige que el ordenamiento jurídico también consagre limitaciones al ejercicio de todos los derechos humanos, en aras del bien común ${ }^{3}$.

En virtud de lo anterior, queda de manifiesto que efectivamente deben existir restricciones al ejercicio de los derechos, limitaciones que deben ser definidas correctamente para su adecuada comprensión.

Para tal efecto, entenderemos por "limitaciones a los derechos fundamentales", aquellas restricciones al ejercicio de un determinado derecho básico, de manera tal que toda pretensión de ejercicio del atributo respectivo que vulnere los limites impuestos por las mismas, es por esencia antijurídica y puede derivar para el titular infractor, en las responsabilidades que para tal efecto, prevea el ordenamiento jurídico positivo ${ }^{4}$.

\section{Clasificación de las Limitaciones}

\section{A LOS DERECHOS FUNDAMENTALES}

Las limitaciones o restricciones a los derechos fundamentales pueden ser clasificadas según diferentes criterios, a saber:

\subsection{Clasificación según las circunstancias en las que operan}

Pueden ser limitaciones ordinarias o extraordinarias:

2.1.1. Son limitaciones ordinarias aquellas que operan siempre, y que afectan el ejercicio de un derecho tanto bajo condiciones de normalidad constitucional, como bajo situaciones de excepción constitucional. Representan la regla general y se aplican en todo momento 5 .

\footnotetext{
${ }^{3}$ Rojas SÁncheZ, et al. (1996), p. 149.

${ }^{4}$ Interesante en este punto es lo señalado por Miguel Ángel Fernández cuando señala sucinta pero acertadamente que "limitar significa restringir o comprimir el ejercicio normal de un derecho". FERNÁNDEZ (2002), p. 695.

${ }^{5}$ Dejamos en claro que, en nuestra opinión, las limitaciones ordinarias no sólo operan en períodos de normalidad institucional, sino en verdad actúan en todo momento. Para ejemplificar este asunto, podríamos decir que bajo un estado de sitio o de asamblea, tampoco es lícito ejercer cultos opuestos a la moral, las buenas costumbres o el orden público; ni pretender iniciar planes de enseñanza contraria a la moral, las buenas costumbres, el orden público y la seguridad nacional, por señalar algunos casos. En resumen, las limitaciones operan siempre (bajo estados de excepción y no). Las limitaciones extraordinarias, en cambio, sólo operan en estados de excepción.
} 
En la Carta Fundamental chilena, encontramos diferentes limitaciones ordinarias a derechos, en diversos numerales del artículo 19, v. gr. el ejercicio libre de todos los cultos reconoce como límite el respeto por la moral, las buenas costumbres y el orden público ${ }^{6}$; el ejercicio de la libertad de enseñanza queda sometido a la moral, las buenas costumbres, el orden público y la seguridad nacional ${ }^{7}$; el derecho a reunirse sólo es válido si se ejerce pacíficamente, sin armas y en el caso de reuniones en lugares de uso público, deberán además respetarse las disposiciones generales de policía ${ }^{8}$; etc. En todos estos casos, las restricciones operan indistintamente en períodos de regularidad institucional, como también en estados de excepción constitucional.

2.1.2. Son limitaciones extraordinarias (también llamadas "excepcionales"), aquellas que se producen sólo durante circunstancias de emergencia social o institucional, y que han dado curso a la declaración de estados de excepción constitucional.

En este sentido, el art. 43 de la $\mathrm{CPR}^{10}$ fija con absoluta claridad las garantías que el Presidente de la República puede suspender o restringir ${ }^{11}$ en virtud de la declaración de cada estado de excepción constitucional.

\footnotetext{
${ }^{6}$ Art. 19 No 6 CPR.

${ }^{7}$ Art. 19 No 11 CPR.

${ }^{8}$ Art. 19 No 13 CPR.

${ }^{9}$ Nogueira (2008), pp. 143-221.

${ }^{10}$ Constitución Politica de la República:

Art. 43: "Por la declaración del estado de asamblea, el Presidente de la República queda facultado para suspender o restringir la libertad personal, el derecho de reunión y la libertad de trabajo. Podrá, también, restringir el ejercicio del derecho de asociación, interceptar, abrir o registrar documentos y toda clase de comunicaciones, disponer requisiciones de bienes y establecer limitaciones al ejercicio del derecho de propiedad.

Por la declaración de estado de sitio, el Presidente de la República podrá restringir la libertad de locomoción y arrestar a las personas en sus propias moradas o en lugares que la ley determine y que no sean cárceles ni estén destinados a la detención o prisión de reos comunes. Podrá, además, suspender o restringir el ejercicio del derecho de reunión. Por la declaración del estado de catástrofe, el Presidente de la República podrá restringir las libertades de locomoción $y$ de reunión. Podrá, asimismo, disponer requisiciones de bienes, establecer limitaciones al ejercicio del derecho de propiedad y adoptar todas las medidas extraordinarias de carácter administrativo que sean necesarias para el pronto restablecimiento de la normalidad en la zona afectada.

Por la declaración del estado de emergencia, el Presidente de la República podrá restringir las libertades de locomoción y de reunión".

${ }^{11}$ El artículo 12 de la Ley Orgánica Constitucional No 18.415 sobre Estados de Excepción Constitucional, del año 1985, establece que: "Se suspende una garantía constitucional cuando temporalmente se impide del todo su ejercicio durante la vigencia de un estado de excepción constitucional. Asimismo, entiéndase que se restringe una garantía constitucional cuando durante la vigencia de un estado de excepción, se limita su ejercicio en el fondo o la forma".
} 
Por su parte, el artículo 27 de la Convención Americana sobre Derechos Humanos $^{12}$ regula también esta materia y establece:

"Art. 27. Suspensión de Garantías: 1. En caso de guerra, de peligro público o de otra emergencia que amenace la independencia o seguridad del Estado Parte, éste podrá adoptar disposiciones que, en la medida y por el tiempo estrictamente limitados a las exigencias de la situación, suspendan las obligaciones contraidas en virtud de esta Convención, siempre que tales disposiciones no sean incompatibles con las demás obligaciones que les impone el derecho internacional y no entrañen discriminación alguna fundada en motivos de raza, color, sexo, idioma, religión u origen social. 2. La disposición precedente no autoriza la suspensión de los derechos determinados en los siguientes artículos: 3 (Derecho al Reconocimiento de la Personalidad Jurídica); 4 (Derecho a la Vida); 5 (Derecho a la integridad Personal); 6 (Prohibición de la Esclavitudy Servidumbre); 9 (Principio de Legalidady de Retroactividad); 12 (Libertad de Conciencia y de Religión); 17 (Protección a la Familia); 18 (Derecho al Nombre); 19 (Derechos del Niño); 20 (Derecho a la Nacionalidad), y 23 (Derechos Politicos), ni de las garantías judiciales indispensables para la protección de tales derechos. 3. Todo Estado Parte que haga uso del derecho de suspensión deberá informar inmediatamente a los demás Estados Parte en la presente Convención, por conducto del Secretario General de la Organización de los Estados Americanos, de las disposiciones cuya aplicación haya suspendido".

La Comisión Interamericana de Derechos Humanos ha destacado que la afectación de derechos fundamentales durante períodos de excepción constitucional, debe cumplir con dos requisitos formales esenciales, a saber, el cumplimento de los principios de proclamación y de notificación. La proclamación "implica una serie de actos de publicación y publicidad indispensables en la determinación de responsabilidades sobre la adopción y ejecución de medidas excepcionales, asi como para que los ciudadanos puedan conocer exactamente la extensión de las limitaciones a sus derechos impuestas por el Estado". La notificación, por su parte, consagrada en el art. 27.3 de la Convención Americana sobre Derechos Humanos ${ }^{13}$, "requiere de los Estados parte informar de manera inmediata a los demás Estados Parte de las

\footnotetext{
${ }^{12}$ Convención Americana sobre Derechos Humanos, de fecha 22 de noviembre de 1969, su instrumento de ratificación fue depositado el día 21 de agosto de 1990, y publicada en el Diario Oficial el 5 de enero de 1991.

${ }^{13}$ Art. 27.3. "Todo Estado Parte que haga uso del derecho de suspensión, deberá informar inmediatamente a los demás Estados Parte en la presente Convención, por conducto del Secretario General de la Organización de los Estados Americanos, de las disposiciones cuya aplicación haya suspendido, de los motivos que hayan suscitado la suspensión y de la fecha en que haya dado por terminada tal suspensión".
} 
disposiciones cuya aplicación haya suspendido, de los motivos que hayan suscitado la suspensión y de la fecha en que haya dado por terminada tal suspensión"14.

En este punto, la Corte Interamericana señaló:

“(...) ha sido aceptado por el Estado que al momento de expedir el Decreto No 86 de 3 de septiembre de 1992, no se informó inmediatamente a los demás Estados Parte en la presente Convención, por conducto del Secretario General de la Organización de los Estados Americanos (en adelante "OEA"), de las disposiciones de la Convención cuya aplicación haya suspendido, de los motivos que hayan suscitado la suspensión y de la fecha en que haya dado por terminada tal suspensión, tal como lo exige el artículo 27.3 de la Convención. Al respecto, la Corte valora positivamente lo manifestado por Ecuador al efectuar su allanamiento, en el sentido de que: [...] los Estados de la región tienen que estar conscientes [de las exigencias del] artículo 27.3 de la Convención Americana [...] obligación que muchas veces es inobserva[d] a por los Estados, y que en este caso fue inobservada por el Estado Ecuatoriano. De ahi el reconocimiento de buena fe que hace el Estado [...]'.

La Corte considera que la obligación internacional que tienen los Estados Parte en la Convención Americana bajo el artículo 27.3 constituye un mecanismo enmarcado en la noción de garantía colectiva subyacente a este tratado, cuyo objeto y fin es la protección del ser humano. Asimismo, constituye una salvaguardia para prevenir el abuso de las facultades excepcionales de suspensión de garantías y permite a los otros Estados Parte apreciar que los alcances de esa suspensión sean acordes con las disposiciones de la Convención. Por ende, la falta de este deber de información implica el incumplimiento de la obligación contenida en el artículo 27.3. Aun en este último supuesto, el Estado no queda eximido de justificar la existencia de la situación de emergencia y la conformidad de las medidas dispuestas al respecto, en los términos señalados anteriormente [...].

En razón de las consideraciones anteriores, la Corte declara que el Estado incumplió las obligaciones contenidas en el artículo 27.1, 27.2 y 27.3 de la Convención, en relación con los derechos y obligaciones contenidos en los artículos 1.1, 2, 4, 8.1 y 25 de la misma". ${ }^{15}$

Proclamación y notificación, por tanto, se vinculan por ser principios que tienen que ver con la publicidad de la declaración de estado de excepción y de las medidas extraordinarias que se adopten. La diferencia entre ambas radica principalmente en que mientras la primera se refiere a una comunicación que, a nivel interno, debe hacer el gobernante que hubiere decretado el estado de excepción a

\footnotetext{
${ }^{14}$ Comisión Interamericana de Derechos Humanos (1998): Observaciones de la Comisión al escrito del Estado de Panamá de 29 de junio de 1998. Caso Baena vs. Panamá. Disponible en: http://www.corteidh. or.cr/docs/casos/baena/replica.pdf [fecha de consulta: 30 de marzo de 2010].

${ }^{15}$ Corte Interamericana de Derechos Humanos. Zambrano Vélez y otros vs. Ecuador (2007).
} 
sus gobernados, la segunda se relaciona con el aviso que el Estado debe realizar a los demás Estados Parte de la Convención Americana sobre Derechos Humanos.

Cabe recordar, finalmente que la Corte Interamericana ha señalado que

"lejos de adoptar un criterio favorable a la suspensión de los derechos, la Convención establece el principio contrario, es decir, que todos los derechos deben ser respetados y garantizados a menos que circunstancias muy especiales justifiquen la suspensión de algunos, en tanto que otros nunca pueden ser suspendidos por grave que sea la emergencia". ${ }^{16}$

\subsection{Clasificación según el origen de la limitación ${ }^{17}$}

Nos referimos a las limitaciones que nacen del respeto por los derechos de las demás personas, a las limitaciones de origen material y a las limitaciones de origen positivo. Mientras las dos primeras se entienden implícitamente insertas en cada derecho, las últimas son las que están expresamente consideradas por el ordenamiento jurídico.

2.2.1. La primera categoría de limitaciones se refiere a aquellas restricciones que nacen del respeto por los derechos fundamentales de los demás sujetos, vale decir, de los demás miembros de la comunidad, circunstancia que impide a cada titular utilizar su derecho en perjuicio de otro. También involucra el cumplimiento del bien común. Al respecto, no debemos olvidar lo dispuesto en el art. 32.2 de la Convención Americana sobre Derechos Humanos: "Los derechos de cada persona están limitados por los derechos de los demás, por la seguridad de todos y por las justas exigencias del bien común, en una sociedad democrática".

$\mathrm{Al}$ ser cada derecho un reflejo de la dignidad intrínseca de cada ser, no es posible pensar en que una de estas prerrogativas esenciales pueda verse afectada por el ejercicio de otro derecho esencial. Preferir los derechos de uno en desmedro de los del otro, va a significar que se privilegia la dignidad de una persona en perjuicio de la dignidad de otro ser humano, lo que atenta, en definitiva, no sólo en contra de la razón sino que sobre todo, en contra de las bases mismas de la teoría de los derechos humanos.

Por lo mismo, ya sea en uno o en otro caso, el ejercicio de un derecho, aun siendo éste un derecho fundamental, debe ser racional y sin dañar los legítimos intereses de otras personas. En caso contrario, su titular transgrede los contornos

${ }^{16}$ El hábeas corpus bajo suspensión de garantías (1987): Corte Interamericana de Derechos Humanos, 30 de enero de 1987, Serie A No 8., párr. 21 (Opinión Consultiva OC-8/87), disponible en: www.corteidh.or.cr/ docs/opiniones/seriea_08_esp.doc, consultado el 30 de marzo de 2010.

${ }^{17}$ Resulta conveniente revisar, en relación con este tema, el esquema propuesto en: PrADO (2007). 
o fronteras que delimitan al derecho y, por lo mismo, su conducta deja de ser amparada por el ordenamiento jurídico.

Finalmente, debemos recordar que ya en los albores de la consagración formal de los derechos humanos, se contempla este tipo de limitaciones. A este respecto, el art. $4^{\circ}$ de la Declaración de Derechos del Hombre y del Ciudadano (1789) señala:

"La libertad consiste en poder hacer todo lo que no perjudica a otro. Asi, el ejercicio de los derechos naturales de cada hombre no tiene otros límites que los que aseguren a los restantes miembros de la sociedad el goce de estos mismos derechos. Estos límites sólo pueden estar determinados por ley”.

2.2.2. Una segunda categoría de limitaciones o restricciones son aquellas de carácter $u$ origen material o físico, y que tienen que ver con las reales posibilidades del Estado, directamente o a través de las instituciones privadas que en virtud del principio de subsidiariedad colaboran con el mismo fin (AFP, Isapres, etc.), para responder a determinados derechos llamados "prestacionales" o de la "segunda generación" 18 .

Estas limitaciones se encuentran referidas exclusivamente a los derechos económicos y sociales, los cuales exigen condiciones suficientes que permitan satisfacerlos razonablemente, de tal modo que la ausencia del referido contexto real significa, en la práctica, una verdadera limitación al ejercicio del derecho en cuestión.

Es relevante destacar que esta clase de restricciones sólo pueden ser toleradas respecto de los mencionados derechos económicos y sociales, entendidos éstos como "derechos generales positivos a acciones fácticas del Estado"19, toda vez que son los únicos dentro del esquema general de derechos fundamentales que dependen exclusivamente de las posibilidades reales de acción del aparato estatal.

Pero aun así, cabe indicar que no todos los derechos sociales se identifican como "derechos prestacionales" que requieran de un esfuerzo presupuestario estatal, ni todos pueden quedar expuestos en su protección a las posibilidades económicas del Fisco ${ }^{20}$. Por lo mismo, es necesario analizar en cada caso, si en verdad se puede considerar legítima o no, la restricción a un derecho económico o social, basada en este tipo de consideraciones.

\footnotetext{
${ }^{18}$ Sobre derechos de primera, segunda y tercera generación, ver: CEA (2002), p. 63.

${ }^{19}$ Arango (2005), p. 37.

${ }^{20}$ Así ocurre, por ejemplo, con los derechos fundamentales que nacen de las relaciones laborales, como la libertad de sindicalización, el derecho a huelga y el derecho a negociar colectivamente; los cuales la doctrina ha ubicado dentro de los derechos sociales. Al respecto, ver: Pereira (2006), p. 302.
} 
$\mathrm{Al}$ respecto, cabe hacer notar que incluso el Pacto Internacional de Derechos Económicos, Sociales y Culturales ${ }^{21}$ introduce este elemento limitativo, cuando dispone en su artículo 1.1:

"Cada uno de los Estados Parte en el presente Pacto se compromete a adoptar medidas, tanto por separado como mediante la asistencia y la cooperación internacionales, especialmente económicas y técnicas, hasta el máximo de los recursos de que disponga, para lograr progresivamente, por todos los medios apropiados, inclusive en particular la adopción de medidas legislativas, la plena efectividad de los derechos aqui reconocidos ${ }^{22}$ ".

2.2.3. Finalmente, podemos reconocer la existencia de aquella clase de limitaciones más habituales y reconocidas, que son las que expresamente están previstas por el ordenamiento jurídico positivo.

A diferencia de las dos anteriores, estas limitaciones no se entienden "implícitamente incorporadas en cada derecho", sino que su origen se encuentra en el ordenamiento jurídico mismo, el cual de forma explícita las nombra y reconoce; $y$ es por este motivo que las insertamos en este criterio taxonómico. Esto no quiere decir que carezcan de fundamento o justificación en valores o principios de gran importancia, sino sólo que, para invocarlas, basta citar algún precepto constitucional o legal para poder recurrir a ellas.

Para ello, tanto los instrumentos internacionales como las constituciones políticas de los diferentes Estados establecen directamente restricciones al ejercicio de determinados derechos, o bien, autorizan o delegan a determinadas autoridades, normalmente en el legislador, para fijarlas. Esta última mención da origen a una tercera clasificación, que es la que se expondrá a continuación.

\subsection{Clasificación según la norma en la que consta la limitación}

Naturalmente, esta clasificación sólo se refiere a aquellas limitaciones establecidas expresamente en el ordenamiento jurídico.

$\mathrm{Al}$ respecto, Robert Alexy indica que el individuo tiene derecho a que su libertad general de acción no sea "restringida por normas que no son elemento constitutivo del orden constitucional, es decir, que no son formal y materialmente acordes con la Constitución"23. En ese sentido, agrega más adelante el mismo autor, "una norma

\footnotetext{
${ }^{21}$ Pacto Internacional de Derechos Económicos, Sociales y Culturales, de 1966.

${ }^{22}$ El énfasis ha sido nuestro.

${ }^{23}$ Alexy (2002), p. 270.
} 
puede ser una restricción de derecho fundamental sólo si es constitucional. Si no lo es, su imposición puede, por cierto, tener el carácter de una intervención pero no de una restricción. Con esto, puede fijarse ya una primera característica: las normas son restricciones de derechos fundamentales sólo si son constitucionales "24.

Bajo esta perspectiva, consistente en que, en el plano interno, sólo la Constitución puede permitir la imposición de limitaciones a los derechos, es que Alexy distingue dos clases de restricciones de los derechos fundamentales ${ }^{25}$ :

2.3.1. Restricciones directamente constitucionales. Se trata de restricciones de rango constitucional. En este caso, la cláusula restrictiva consta en la propia Carta Fundamental, sin existir delegación a otra autoridad o persona para imponer tales limitaciones.

En algunos casos, las restricciones directamente constitucionales son bastante evidentes. En Chile, por ejemplo, la libertad de culto reconoce como limitación el respeto a la moral, las buenas costumbres y el orden público ${ }^{26}$; mismas limitaciones que, además de la seguridad nacional, sufre el ejercicio de la libertad de enseñanza ${ }^{27}$. Por su parte, el derecho de petición tiene como única limitación la de proceder en términos respetuosos y convenientes ${ }^{28}$; mientras que la libertad de asociación se ve restringida, al prohibirse las asociaciones contrarias a la moral, al orden público y a la seguridad naciona ${ }^{29}$; por nombrar algunos casos. Todas estas restricciones tienen un reconocimiento constitucional directo.

En otros casos, en cambio, la calidad de ser limitaciones directamente constitucionales, es menos nítido, como cuando en algunas Constituciones se hace referencia a los "derechos de terceros" como restricción al ejercicio de un determinado derecho ${ }^{30}$. En tal caso, la limitación será directamente constitucional cuando

\footnotetext{
${ }^{24}$ Íd., p. 272.

${ }^{25}$ Íd., pp. 276-286.

${ }^{26}$ Art. 19 No 6, Constitución Politica de la República.

${ }^{27}$ Art. 19 No 11, Constitución Politica de la República.

${ }^{28}$ Art. 19 No 14, Constitución Politica de la República.

${ }^{29}$ Art. 19 No 15, Constitución Política de la República.

${ }^{30}$ Es el caso, por ejemplo, de lo dispuesto en el art. 19 № 7, letra a) de la Constitución Política chilena: "Toda persona tiene derecho a entrar y residir y permanecer en cualquier lugar de la República, trasladarse de uno a otro y entrar y salir de su territorio, a condición de que se guarden las normas establecidas en la ley y salvo siempre el perjuicio de terceros"; en el art. 2.1. de la Ley Fundamental de Bonn: "Toda persona tiene el derecho al libre desarrollo de su personalidad siempre que no viole los derechos de otra ni atente contra el orden constitucional o la ley moral"; o en el art. 16 de la Constitución colombiana: "Todas las personas tienen derecho al libre desarrollo de su personalidad sin más limitaciones que las que imponen los derechos de los demás y el orden jurídico"; por citar algunos casos (los énfasis han sido nuestros).
} 
los derechos que generan una restricción respecto de otro, tienen consagración constitucional, en caso contrario, serán limitaciones sólo indirectamente constitucionales.

2.3.2. Restricciones indirectamente constitucionales. Son aquellas cuya imposición está autorizada por la Constitución. Vale decir, no se trata de restricciones expresamente establecidas en la Norma Fundamental, sino que es ésta la que genera competencia en favor de la ley u otro tipo de norma, para que sean ellas las que impongan la limitación respectiva.

Según Alexy, "la competencia para imponer restricciones indirectamente constitucionales se expresa de manera clarísima en las cláusulas de reserva explícitas", siendo estas últimas "aquellas disposiciones iusfundamentales o partes de disposiciones iusfundamentales que autorizan expresamente intervenciones, restricciones o limitaciones $^{\text {'31. }}$.

En la Constitución Política chilena, tal como veremos, existen variadas cláusulas de reserva explícitas, por medio de las cuales se habilita especialmente a la ley para generar restricciones a determinadas garantías. En otras, la autorización se dirige a autoridades administrativas, e incluso a jueces y particulares.

\section{LAS CONDICIONES PARA LA LIMITACIÓN \\ DE LOS DERECHOS FUNDAMENTALES}

En este punto, me referiré específicamente a las limitaciones establecidas en el ordenamiento jurídico positivo.

La expresión "condiciones de limitación de los derechos fundamentales" la he extraído de lo propuesto por Luis Prieto Sanchís ${ }^{32}$, quien plantea que las facultades de limitación de esa clase de derechos, quedan sometidas a dos circunstancias especiales: la cláusula del contenido esencial de los derechos y la exigencia de justificación.

A su vez, se puede señalar que son condiciones de limitación de los derechos fundamentales, los presupuestos o requisitos que deben observar las autoridades llamadas a imponer, con carácter general, restricciones ordinarias o extraordinarias a esa categoría de derechos. Son una especie de "límites a la potestad limitadora", en el entendido que ni el constituyente ni el legislador, ni cualquier otra persona o autoridad que tenga facultades para restringir los derechos fundamentales, puede actuar con absoluta libertad, a su arbitrio, o con poderes absolutos.

${ }^{31}$ AleXy (2002), p. 282.

32 Prieto (2003), pp. 232-241. 
Por lo mismo, en el presente documento, siguiendo a Prieto Sanchís, pero ampliando a su vez sus postulados, se reconocerán las siguientes condiciones para la limitación de los derechos fundamentales ${ }^{33}$ :

\subsection{Condición de carácter competencial}

En el plano interno, es materia de dominio constitucional el establecimiento de limitaciones a los derechos fundamentales.

Por lo mismo, el legislador u otra autoridad sólo podrán proceder a limitar un derecho fundamental, cuando previamente haya sido constitucionalmente habilitado para ello. Esta habilitación o autorización sólo podrá provenir de la Carta Fundamental, en virtud del principio de supremacía constitucional consagrado en el artículo $6^{\circ}$ de nuestro Código Político ${ }^{34}$; como también del art. 19 No 26 de la Constitución, que dispone que los preceptos legales podrán limitar las garantías que establezca la Constitución, sólo cuando ésta así lo haya autorizado ${ }^{35}$. De no existir tal habilitación constitucional, el legislador carece de competencia para establecer limitaciones o restricciones a los derechos fundamentales.

No debemos olvidar en este punto que respecto de ciertas garantías, la Constitución Política, incluso, ha hecho claras diferencias en cuanto al rol que debe cumplir el legislador. El caso más notable es lo que ocurre con el derecho a desarrollar cualquiera actividad económica. En lo referente a esta garantía, la ley sólo

\footnotetext{
${ }^{33}$ También es relevante el señalamiento de las condiciones que, a la luz del sistema americano de protección de derechos, realizó la Corte Interamericana de Derechos Humanos en la Opinión Consultiva OC-6/86 del 9 de mayo de 1988, denominada "La expresión 'leyes' en el artículo 30 de la Convención Americana sobre Derechos Humanos": "Al leer el artículo 30 en concordancia con otros en que la Convención autoriza la imposición de limitaciones o restricciones a determinados derechos y libertades, se observa que exige para establecerlas el cumplimiento concurrente de las siguientes condiciones: (a) que se trate de una restricción expresamente autorizada por la Convención y en las condiciones particulares en que la misma ha sido permitida; (b) que los fines para los cuales se establece la restricción sean legitimos, es decir, que obedezcan a 'razones de interés general'y no se aparten del 'propósito para el cual han sido establecidas'. Este criterio teleológico, cuyo análisis no ha sido requerido en la presente consulta, establece un control de desviación de poder; y (c) que tales restricciones estén dispuestas por las leyes y se apliquen de conformidad con ellas" (párrafo 18).

${ }^{34}$ Constitución Politica de la República:

Artículo 60: "Los órganos del Estado deben someter su acción a la Constitución y a las normas dictadas conforme a ella, y garantizar el orden institucional de la República.

Los preceptos de esta Constitución obligan tanto a los titulares o integrantes de dichos órganos como a toda persona, institución o grupo.

La infracción de esta norma generará las responsabilidades y sanciones que determine la ley".

${ }^{35}$ Constitución Politica de la República:

Artículo 19: "La Constitución asegura a todas las personas: No 26: La seguridad de que los preceptos legales que por mandato de la Constitución regulen o complementen las garantías que ésta establece o que las limiten en los casos en que ella lo autoriza, no podrán afectar los derechos en su esencia, ni imponer condiciones, tributos o requisitos que impidan su libre ejercicio". (El subrayado es nuestro).
} 
puede regular el derecho, mas no limitarlo. De hecho, al menos en dos ocasiones, el Tribunal Constitucional chileno se ha pronunciado al respecto señalando que "sujetar una actividad a una regulación significa establecer la forma o normas conforme a las cuales debe realizarse, pero en caso alguno puede ser que, bajo el pretexto de regular, se llegue a impedir el ejercicio de una actividad"36, y "en caso alguno, bajo pretexto de 'regular' un accionar privado, se pueden llegar hasta obstaculizar e impedir la ejecución de los actos lícitos amparados por el derecho consagrado en el artículo 19 No 21 de la Constitución Política" 37.

En casos muy específicos, la autoridad administrativa también cuenta con facultades constitucionales para restringir o limitar derechos. Así sucede con el derecho de las confesiones religiosas para erigir y conservar templos y sus dependencias bajo las condiciones de seguridad e higiene fijadas no sólo por las leyes, sino también "por las ordenanzas", norma esencialmente de carácter administrativo ${ }^{38}$; y con el derecho de reunión, que cuando se ejerce en lugares de uso público, deberá darse cumplimiento a las disposiciones generales de policía ${ }^{39}$.

Por otra parte, los jueces también pueden estar autorizados constitucionalmente para limitar ciertos derechos, y bajo determinadas circunstancias. Así, en el caso chileno, podrán ordenar allanamientos o interceptar, abrir o registrar comunicaciones (art. 19 No 5 de la CPR); o decretar la privación o restricción de libertad en los casos y formas y en la forma determinados por la Constitución y las leyes (art. 19 No 7 de la CPR), a modo de ejemplo.

La habilitación a la que hacemos referencia en este apartado debe ser expresa y, específicamente, consagrada por el Constituyente, a través de las llamadas "normas de competencia” ${ }^{\prime 40}$, de modo que el órgano dotado de tal facultad sólo podrá introducir limitaciones exclusivamente respecto de los derechos claramente indicados en la Carta Fundamental.

Un caso especial lo reviste la posibilidad que personas privadas -individuales o colectivas- queden revestidas también de atribuciones para limitar o restringir determinados derechos. En el caso chileno, por ejemplo, los colegios profesionales constituidos en conformidad a la ley y que digan relación con las profesiones que, según la ley, requieran grado o título universitario, están facultados para conocer las reclamaciones que se interpongan sobre la conducta ética de sus miembros (art. 19 No 16, párrafo cuarto de la CPR), lo cual puede significar, en la práctica,

\footnotetext{
${ }^{36}$ Tribunal Constitucional chileno: Sentencia del 21 de abril de 1992, Rol No 146, Considerando No 9.

${ }^{37}$ Tribunal Constitucional chileno: Sentencia del 6 de abril de 1993, Rol o 167, Considerando № 14.

${ }^{38}$ Art. 19 No 6, inciso segundo de la Constitución Política de la República.

${ }^{39}$ Art. 19 No 13, inciso segundo, de la Constitución Política de la República.

${ }^{40}$ AleXy (2002), p. 272.
} 
la posibilidad para que dichas instituciones puedan establecer restricciones a la libertad de trabajo.

En virtud del criterio de la competencia, podemos concluir que: (a) un órgano estatal sólo podrá limitar un derecho fundamental cuando haya sido expresamente facultado para ello por la Constitución; (b) a contrario sensu, si la Carta Fundamental no prevé que el ejercicio de un determinado derecho fundamental pueda ser restringido por el legislador u otra autoridad, entonces no será válida la limitación que se imponga para aquél; (c) no es correcta la simple afirmación que "la limitación de los derechos fundamentales debe concretarse por ley", como si el legislador estuviere siempre habilitado para ello, toda vez que no existe una autorización genérica en tal sentido ${ }^{41}$, y (d) lo anterior no obsta a que un derecho esencial pueda ser comprimido o restringido a partir de criterios sociales o materiales, según lo revisáramos en páginas anteriores.

\subsection{Condición de carácter internacional}

Esta condición se vincula con el respeto al llamado "bloque de constitucionalidad de derechos fundamentales" 42 , el cual supone que esta clase de derechos no se encuentran establecidos ni garantizados sólo a nivel interno, sino que también existe una consagración en el campo del derecho internacional, cuyas normas deben ser respetadas, preferentemente, por los Estados. De esta manera, y a la luz de lo dispuesto en el artículo $5^{\circ}$ inciso segundo de la Constitución Política de la República ${ }^{43}$, todos los órganos del Estado se ven sometidos al deber de ajustar su actuación al respeto de tales atributos fundamentales.

\footnotetext{
${ }^{41}$ En este sentido, destaco la afirmación de Jorge Precht: “... en Chile, parece evidente que las limitaciones a los derechos fundamentales deben ser impuestas por ley, con clara habilitación constitucional al legislador para hacerlo, sin afectar los derechos en esencia y a través de medidas necesarias, en una sociedad democrática, para conseguir un fin legitimo y además proporcionales en relación a ese fin legitimo": РRECHT (2001), p. 279.

${ }^{42}$ El bloque constitucional de derechos fundamentales encuentra su mejor definición en Nogueira, quien lo define como "el conjunto de derechos de las personas (atributos) asegurados por fuente constitucional o por fuentes del derecho internacional de los derechos humanos (tanto el derecho convencional como el derecho consuetudinario $y$ los principios de ius cogens) y los derechos implícitos expresamente incorporados a nuestro ordenamiento jurídico por la vía del artículo 29 literal c) de la [Convención Americana sobre Derechos Humanos], todos los cuales constituyen límites a la soberanía, como lo especifica categóricamente el artículo $5^{\circ}$ inciso segundo de la Constitución chilena vigente". NogueIra (2008), p. 37.

43 Constitución Política de la República:

Art. $5^{\circ}$ inciso segundo: "El ejercicio de la soberanía reconoce como limitación el respeto a los derechos esenciales que emanan de la naturaleza humana. Es deber de los órganos del Estado respetar y promover tales derechos, garantizados por esta Constitución, así como por los tratados internacionales ratificados por Chile y que se encuentren vigentes".
} 
Por lo anterior, la instalación jurídica de una determinada restricción debe siempre considerar el cumplimiento de las obligaciones internacionales contraídas por el Estado. En este sentido resulta imperioso considerar que el derecho internacional restringe a la potestad normativa de los órganos nacionales, al menos en cuatro sentidos: el derecho nacional no podrá limitar un derecho cuya restricción esté prohibida en el derecho internacional, ni tampoco en casos o hipótesis diferentes, o en una medida mayor, o de un modo distinto al establecido en el derecho internacional.

Antônio Cançado Trindade enfatiza a propósito de esta relación entre el derecho interno y el internacional: "descartada la compartimentalización, teórica y estática, de la doctrina clásica, entre el derecho internacional y el derecho interno, hoy día, con la interacción dinámica entre uno y otro en el presente dominio de protección, es el propio Derecho que se enriquece -y justifica- en la medida en que se cumple su misión última de hacer justicia. En el presente contexto, el derecho internacional y el derecho interno interactúan y se auxilian mutuamente en el proceso de expansión y fortalecimiento del derecho de protección del ser humano. En este umbral del siglo XXI, es alentador constatar que el derecho internacional y el derecho interno al fin caminan juntos y apuntan en la misma dirección, coincidiendo en el propósito básico y último de la protección del ser humano en todas y cualesquiera circunstancias" ${ }^{34}$.

Una de las normas internacionales más relevantes en este punto es la del artículo 30 de la Convención Americana sobre Derechos Humanos, la cual establece un requisito básico que deben tener las limitaciones a los derechos:

"Artículo 30. Alcance de las Restricciones. Las restricciones permitidas, de acuerdo con esta Convención, al goce y ejercicio de los derechos y libertades reconocidas en la misma, no pueden ser aplicadas sino conforme a leyes que se dictaren por razones de interés general y con el propósito para el cual han sido establecidas".

En relación con esta última norma, la Corte Interamericana de Derechos Humanos ha dicho que "al leer el artículo 30 en concordancia con otros en que la Convención autoriza la imposición de limitaciones o restricciones a determinados derechos y libertades, se observa que exige para establecerlas el cumplimiento concurrente de las siguientes condiciones: a. Que se trate de una restricción expresamente autorizada por la Convención y en las condiciones particulares en que la misma ha sido permitida; $b$. Que los fines para los cuales se establece la restricción sean legitimos, es decir, que obedezcan a 'razones de interés general' y no se aparten del 'propósito para el cual han sido establecidas'. Este criterio teleológico (...) establece un control

${ }^{44}$ Cançado Trindade (2006), p. 315. 
por desviación de poder; y c. Que tales restricciones estén dispuestas por las leyes y se apliquen de conformidad con ellas" ${ }^{35}$.

La Corte también aborda el problema relativo a la delimitación del concepto de "interés general", al que alude el mencionado art. 30 del Pacto de San José de Costa Rica, cuando indica:

"La Convención no se limita a exigir una ley para que las restricciones al goce y ejercicio de los derechos y libertades sean jurídicamente lícitas. Requiere, además, que esas leyes se dicten 'por razones de interés general y con el propósito para el cual han sido establecidas. (...) El requisito según la cual las leyes han de ser dictadas por razones de interés general significa que deben haber sido adoptadas en función del 'bien común' (art. 32.2), concepto que ha de interpretarse como elemento integrante del orden público del Estado democrático, cuyo fin principal es la protección de los derechos esenciales del hombre y la creación de circunstancias que le permitan progresar espiritual y materialmente y alcanzar la felicidad' ('Declaración Americana de los Derechos y Deberes del Hombre' Considerandos, párr. 1). 'Bien común'y 'orden público' en la Convención son términos que deben interpretarse dentro del sistema de la misma, que tiene una concepción propia según la cual los Estados americanos 'requieren la organización política de los mismos sobre la base del ejercicio efectivo de la democracia representativa' (Carta de la OEA, art. 3.d); y los derechos del hombre, que 'tienen como fundamento los atributos de la persona humana', deben ser objeto de protección internacional (Declaración Americana, Considerandos, párr. 2; Convención Americana, Preámbulo, párr. 2) '6.

Que los derechos puedan ser limitados en consideración al “interés general”, no significa en ningún caso que este interés sea superior a los derechos humanos o a la dignidad de la persona, sino sólo implica que los derechos sólo podrán limitarse o restringirse "excepcionalmente", en atención a dicho interés general. Además, estas restricciones deberán ser establecidas en términos de generalidad normativa, de modo tal que no signifiquen sacrificios o cargas particulares, atentando contra la igualdad ante la ley y de la proscripción de toda forma de arbitrariedad.

Finalmente, el mismo Tribunal internacional ha señalado "que la palabra leyes en el artículo 30 de la Convención significa norma jurídica de carácter general, ceñida al bien común, emanada de los órganos legislativos constitucionalmente previstos y democráticamente elegidos, y elaborada según el procedimiento establecido por las constituciones de los Estados Partes para la formación de las leyes"'\$7.

\footnotetext{
${ }^{45}$ Corte Interamericana de Derechos Humanos: Opinión Consultiva La expresión "leyes" en el artículo 30 de la Convención Americana sobre Derechos Humanos (1986).

${ }^{46}$ Íd., párrafos 28-30.

${ }^{47}$ Íd., punto resolutivo.
} 
No podemos ignorar -luego del criterio de la Corte Interamericana recién expuesto- la reflexión acerca de aquellos casos ya revisados, en los que la Carta Fundamental ha autorizado a que órganos administrativos puedan limitar derechos fundamentales (art. 19 números 6 y 13 de la Constitución Política). Si para la Corte, las leyes que puedan establecer restricciones a los derechos y libertades reconocidos en la Convención Americana sobre Derechos Humanos deben provenir "de los órganos legislativos constitucionalmente previstos", bien podríamos concluir que en este punto específico, Chile se encuentra en situación de incumplimiento del mencionado instrumento internacional.

\subsection{Condición de carácter material}

Ésta se refiere al respeto por el contenido esencial del derecho, el cual en el caso chileno se encuentra expresamente protegido por el artículo 19 No 26 de la Carta Fundamental -norma que, como vimos, también establece una regla de competencia-, el que dispone:

"La Constitución asegura a todas las personas, la seguridad de que los preceptos legales que por mandato de la Constitución regulen o complementen las garantías que ésta establece o que las limiten en los casos en que ella lo autoriza, no podrán afectar los derechos en su esencia, ni imponer condiciones, tributos o requisitos que impidan su libre ejercicio".

La protección por el contenido esencial de los derechos fundamentales nace, positivamente, en Alemania. En efecto, el artículo 19 de la Ley Fundamental de Bonn de 1949 dispone, en lo pertinente:

"(1) Cuando de acuerdo con la presente Ley Fundamental un derecho fundamental pueda ser restringido por ley o en virtud de una ley, ésta deberá tener carácter general y no estar limitada al caso individual. Además, la ley deberá mencionar el derecho fundamental indicando el artículo correspondiente. (2) En ningún caso un derecho fundamental podrá ser afectado en su contenido esencial".

Como se aprecia, la normativa germana sólo alude a las leyes limitadoras de derechos, mientras que la disposición constitucional chilena se refiere, además, a las normas que regulen o complementen las garantías constitucionales, por lo que la norma criolla es más amplia. Una segunda diferencia entre ambas regulaciones, viene dada por la exigencia que se aprecia en la Ley Fundamental alemana en el sentido que las mencionadas leyes deberán tener carácter general y determinado, o sea, no podrán estar circunscritas a un caso individual y, además, deberán señalar con precisión, incluso, el artículo correspondiente al derecho que se limitará, condiciones ambas que no se encuentran en nuestra Constitución Política. 
Podemos con mucha fuerza afirmar que si bien la esencia de las cosas es siempre una sola, bien cabe distinguir el núcleo fundamental de cada derecho (el cual debe ser identificado aisladamente respecto de los demás derechos), y una suerte de núcleo o sustento genérico, el fundamento básico y primordial de todos estos derechos básicos.

Resulta muy sugerente en este punto, lo expuesto por José Luis Cea, que es capaz de identificar una especie de raíz común a los diferentes núcleos esenciales de los derechos, señalando que la esencia de la fuente esencial de los valores y los derechos constitucionales se encuentra en la dignidad humana, y que las limitaciones y restricciones no pueden convertirse en regla general, de la cual resulte que la libertad e igualdad de las personas desaparezca o quede comprimida a un ámbito mínimo ${ }^{48}$. Por este motivo, el autor identifica la garantía consagrada en el mencionado numeral 26 del artículo 19 de nuestro Código Político, como el derecho "a la seguridad jurídica"

En un sentido similar se pronuncia el autor portugués José Carlos Vieira de Andrade, quien señala que el límite absoluto del legislador en su facultad para restringir derechos es "a dignidade do homem concreto como ser livre" más allá de la decisión que un Estado adopte a la hora de fijar los márgenes de la potestad limitativa, no debe perderse de vista, en palabras de Magdalena Lorenzo Rodríguez Armas, "la idea del hombre como ser digno y libre, que está en la base de los derechos y que constituye, muy especialmente, la esencia de los derechos, libertades y garantías", la cual "tiene que ser vista como un limite a ese poder de restricción ${ }^{51}$ ".

La misma autora Magdalena Lorenzo Rodríguez-Armas lo enfatiza:

"El contenido esencial de los derechos fundamentales y de las libertades públicas es la expresión jurídico-positivizada del valor intrinseco de cada uno de esos derechos y libertades reconocidos en la Constitución, resultando de la conjunción entre el valor supremo de la dignidad humana (...) y el núcleo esencial propio de cada derecho o libertad que tiene que ver con sus manifestaciones particulares (internas y externas o relativas a su ejercicio)".52

La garantía del respeto por el contenido esencial de los derechos aparece, por lo tanto, como una garantía frente al propio legislador, como una norma de clausura que viene en restringir notablemente el campo de acción de la ley. En términos similares se ha pronunciado, por ejemplo, Eduardo Soto Kloss en un voto disidente incorporado a un fallo del Tribunal Constitucional chileno:

${ }^{48}$ CEA (2002), p. 599.

${ }^{49}$ Íd., pp. 607 y 608.

${ }^{50}$ Citado por: Lorenzo (1996), p. 158.

${ }^{51}$ Íd., p. 158.

52 Íd, p. 242. 
"de admitirse que sea introducida en el ordenamiento jurídico de la República una tal disposición, ella se configura como una amenaza permanente al contenido esencial del derecho a la libertad personal, asegurado explicitamente por la Constitución en su artículo 19, No 26, que es como el 'arco de bóveda'o 'piedra angular' que ha previsto el constituyente de 1980 para asegurar el ejercicio real y efectivo de los derechos fundamentales frente a los embates del legislador, al mismo tiempo que encuadrar a éste en el debido e insoslayable y efectivo respeto a la Constitución" ${ }^{53}$

Por su parte, y aun con mayor claridad, el mismo Tribunal Constitucional ha indicado que "un derecho es afectado en su esencia cuando se le priva de aquello que le es consustancial, de manera tal que deja de ser reconocible 4 ".

Es una cuestión, por tanto, de “magnitud" de la limitación, como dirá en otra sentencia el propio Tribunal Constitucional, de manera tal que, por ejemplo:

"si el acto de regulación o limitación afecta de una magnitud significativa las facultades o atributos esenciales del propietario, éste podrá argumentar que se le ha privado del dominio, pues ya no puede hacer las cosas esenciales que éste conllevaba ${ }^{355}$.

Así las cosas, reconocida la atribución constitucional con la que cuenta un órgano expresamente habilitado para restringir o limitar un derecho, éste en caso alguno podrá afectar este núcleo fundamental, el cual deberá permanecer inalterado por la acción restrictiva.

\subsection{Condiciones de carácter lógico}

Finalmente, las limitaciones efectuadas a los derechos esenciales deberán ser debidamente justificadas y proporcionales.

Que las limitaciones sean justificadas, quiere decir que deben tener una causa o motivo jurídico concreto, susceptible de ser comprendido y, por lo mismo, de ser revisado. A su vez, deben ser razonadas y razonables, y en ningún caso, arbitrarias o caprichosas. Normalmente, tales restricciones pueden provenir de la necesidad de dar protección a otros derechos ${ }^{56}$, o bien a intereses y valores comunes a la sociedad $^{57}$. La exigencia consistente en la ausencia de arbitrariedad se entiende

\footnotetext{
53 Tribunal Constitucional chileno: Rol No 248 (1996).

${ }^{54}$ Tribunal Constitucional chileno: Rol No 43 (1987). El énfasis es nuestro.

55 Tribunal Constitucional chileno, Rol No 505 (2007). Considerando № 22.

${ }^{56}$ Por ejemplo, el derecho consagrado en el artículo $8^{\circ}$ inciso segundo de la CPR, a conocer los actos y resoluciones de los órganos del Estado, así como sus fundamentos y los procedimientos que utilicen, puede verse limitado por una ley de quórum calificado que establezca la reserva o secreto de aquéllos o de éstos, cuando la publicidad afectare, entre otras cosas, a los derechos de las personas.

${ }^{77}$ Ejemplos: "La ley podrá establecer restricciones especificas al ejercicio de determinados derechos o libertades para proteger el medio ambiente" (art. 19 No 8, inciso 2० CPR); o "nadie puede, en caso alguno, ser privado
} 
implícitamente incorporada como tal, a partir de la prohibición genérica del inciso segundo del artículo 19 numeral 2 de la CPR, el cual dispone "[n] la ley ni autoridad alguna podrán establecer diferencias arbitrarias".

La necesidad de justificar las limitaciones a los derechos emana como consecuencia de la circunstancia que ellas son por naturaleza excepcionales, y para que sean válidas deberán estar amparadas en criterios de razonabilidad.

Por su parte, que sean proporcionales, significa que las restricciones deben ser adecuadas. En otras palabras, según Häberle, "el principio de proporcionalidad exige que los medios aplicados para lograr el fin a que se aspira sean apropiados" ${ }^{58}$, para quien la cuestión de proporcionalidad surge luego de una adecuada ponderación de los bienes jurídicos en juego.

En esa misma línea, la proporcionalidad supone que el daño o deterioro que se produzca al ejercicio del derecho sea el mínimo en consideración al fin buscado.

$\mathrm{Al}$ respecto, en materia de medidas adoptadas bajo estados de excepción constitucional, el criterio de la proporcionalidad de las mismas es especialmente relevante, debido a la intensidad de las facultades que detentan las autoridades respectivas. Por lo mismo, tanto el Pacto Internacional de Derechos Civiles y Políticos ${ }^{59}$ como la Convención Americana sobre Derechos Humanos ${ }^{60}$ lo consagran expresamente entre sus normas.

Por su parte, a partir de la reforma constitucional introducida por la Ley No 20.050 del año $2005^{61}$, nuestra Carta Fundamental contempla expresamente que "No obstante, respecto de las medidas particulares que afecten derechos consti-

de su propiedad, del bien sobre que recae o de algunos de los atributos o facultades esenciales del dominio, sino en virtud de ley general o especial que autorice la expropiación por causa de utilidad pública o de interés nacional, calificada por el legislador" (art. 19 № 24, inciso $3^{\circ}$ CPR).

${ }^{58}$ HäBERLE (2003), p. 68.

${ }^{59}$ Pacto Internacional de Derechos Civiles y Políticos, 1972. Art. 4.1.: "En situaciones excepcionales que pongan en peligro la vida de la nación y cuya existencia haya sido proclamada oficialmente, los Estados Parte en el presente Pacto podrán adoptar disposiciones que en la medida estrictamente limitada a las exigencias de la situación, suspendan las obligaciones contraidas en virtud de este Pacto, siempre que tales disposiciones no sean incompatibles con las demás obligaciones que les impone el derecho internacional y no entrañen discriminación alguna fundada únicamente en motivos de raza, color, sexo, idioma, religión u origen social".

${ }^{60}$ Convención Americana sobre Derechos Humanos. Art. 27.1. "En caso de guerra, de peligro público o de otra emergencia que amenace la independencia o seguridad del Estado Parte, éste podrá adoptar disposiciones que, en la medida y por el tiempo estrictamente limitados a las exigencias de la situación, suspendan las obligaciones contraidas en virtud de esta Convención, siempre que tales disposiciones no sean incompatibles con las demás obligaciones que les impone el derecho internacional y no entrañen discriminación alguna fundada en motivos de raza, color, sexo, idioma, religión u origen social".

${ }^{61}$ Ley No 20.050. Publicada en el Diario Oficial, el 26 de agosto de 2005. 
tucionales, siempre existirá la garantía de recurrir ante las autoridades judiciales a través de los recursos que corresponda" (art. 45, inciso primero, segunda parte, CPR). Con ello, estimamos, que a partir de esta modificación constitucional, los órganos judiciales podrán calificar, además de los fundamentos y circunstancias de las medidas que se adopten durante un estado de excepción constitucional, su justificación y proporcionalidad ${ }^{62}$, situación inexistente en el panorama constitucional anterior.

\section{LAS LIMITACIONES FÁCTICAS \\ DE LOS DERECHOS FUNDAMENTALES}

\subsection{Concepto de limitaciones fácticas de los derechos fundamentales}

Habiendo identificado el concepto de las limitaciones a los derechos fundamentales, su taxonomía y condiciones, corresponde resumir algunas ideas que nos permitirán abordar una conceptualización básica en torno a lo que llamaremos "limitaciones fácticas de los derechos fundamentales".

En primer lugar, debemos recordar que la idea de la limitación de un derecho fundamental involucra la restricción en el legítimo ejercicio del mismo, de modo tal que el intento por actuar bajo su amparo y en la hipótesis de restricción, en verdad se trata de una conducta de su titular, contraria al ordenamiento jurídico y, por lo mismo, susceptible de consecuencias desfavorables para el mismo.

Luego, asumir que en verdad existen diferentes clases de limitaciones de los derechos fundamentales, y que éstas para que sean válidas deben dar cumplimiento a las condiciones de validez que hemos acabado de reseñar.

En suma, la limitación de esta esencial clase de derechos constituye una institución jurídicamente reconocida, perfectamente identificada, y con sus contornos muy bien delineados en el área del Derecho.

Por lo mismo, creemos que en todos aquellos casos en los que la institucionalidad jurídico-política de un país, impone o tolera la imposición de una determinada restricción que no cumpla las condiciones recién planteadas, lo que hace es alejarse del marco jurídico, apartando su conducta de toda legitimidad, y desconociendo el principio de servicialidad del Estado y de sus órganos ${ }^{63}$.

${ }^{62}$ En términos similares, en: Ríos (2005), p. 339.

${ }^{63}$ Constitución Política de la República:

Art. $1^{\circ}$ inciso cuarto: "El Estado está al servicio de la persona humana y su finalidad es promover el bien común, para lo cual debe contribuir a crear las condiciones sociales que permitan a todos y a cada uno de los integrantes de la comunidad nacional su mayor realización espiritual y material posible, con pleno respeto a los derechos y garantías que esta Constitución establece". 
Ahora bien, la hipótesis que intentaremos demostrar en las próximas páginas es que, al menos en Chile, los Tribunales de Justicia han reconocido limitaciones a los derechos fundamentales, que no cumplen con las condiciones ya expuestas $y$, por lo tanto, han dado origen o validado la existencia de restricciones que, en rigor, son ilegítimas.

Será precisamente a esta clase de restricciones, a las cuales llamaremos "limitaciones fácticas" ${ }^{64}$, las cuales deben entenderse como: "todas aquellas restricciones a los derechos fundamentales de las personas que, si bien no cumplen con las condiciones que deben revestir para su validez, igualmente son establecidas o aceptadas como formalmente legitimas por los órganos de un Estado".

\subsection{Análisis de la denominación}

En relación con la expresión "limitaciones fácticas de los derechos fundamentales", se puede advertir lo siguiente:

a) Son efectivamente limitaciones a los derechos fundamentales, toda vez que significan una restricción, un impedimento para el ejercicio de los mismos.

No obstante, dejamos constancia que, según algunos autores, tal como lo dijéramos más arriba respecto de Alexy, en rigor éstas no son restricciones o limitaciones, sino que en verdad, intervenciones de quien pretende imponerlas.

La diferencia entre lo que hemos llamado "limitación fáctica", con la "intervención" de Alexy, radica en la posición jurídica que ocupan las distintas condiciones de la que deben estar revestidas las diferentes restricciones a los derechos fundamentales impuestas por el Estado.

En efecto, si estimamos que tales condiciones (competenciales, internacionales, materiales y lógicas) son condiciones de existencia, en tal caso, su falta genera que dichas limitaciones en verdad no sean tales, sino meras intervenciones. Si consideramos, en cambio, que son condiciones de validez, entonces diremos que tales restricciones han nacido, pero que ellas son materialmente ilegítimas o contrarias a derecho.

El caso es que, al menos en Chile, las referidas limitaciones fácticas en verdad existen, al punto que han sido impuestas, reconocidas o promovidas por los órganos estatales, circunstancia que constituye una realidad indiscutible. Por lo mismo, nada se obtiene con desconocer un hecho verídico, asignándole una denominación que sólo disfraza una verdad estatal incontrarrestable.

${ }^{64}$ El autor de este trabajo ya había utilizado previamente esta expresión en: TórTORA (2005), pp. 199-247. 
b) Se trata de limitaciones "fácticas". Esta denominación quiere decir que genéticamente no son constitucionales, toda vez que no tienen su origen directa ni indirectamente en la Carta Fundamental.

Son restricciones, por lo tanto, cuya existencia sólo se da en el mundo de los hechos, mas no en el Derecho. Por lo mismo, aun cuando deberían estar conforme a Derecho, no constituyen instituciones jurídicas reguladas ni amparadas por el ordenamiento jurídico.

Junto a los decretos leyes, a los gobiernos de facto y a las figuras civiles putativas, las limitaciones fácticas a los derechos fundamentales pertenecen a cierta categoría especial de realidades que, sin tener reconocimiento positivo, han terminado por ser toleradas, por diversos motivos, por la institucionalidad.

En relación con el término "fáctico", Arturo Fermandois lo utiliza en otro sentido, pero que de todos modos es interesante destacar. El autor habla de "las vías de infracción fáctica de la garantía del art. 19 No 21 de la Constitución Política" (los derechos a desarrollar cualquiera actividad económica y a que se respeten las normas relativas al Estado empresario). Para él, se trata de "vías extrajurídicas, de hecho, que el Estado ha venido utilizando para desbordar su estatuto constitucional". Cita dos situaciones que se repiten en este sentido: (1) cuando una empresa u organismo estatal desarrolla actividades empresariales diferentes o análogas a aquellas que la ley le autorizó a realizar; y (2) cuando una empresa u organismo estatal participa de determinadas actividades empresariales, a través de terceros, en asociación, agrupación, convención, u otra fórmula jurídica o de hecho ${ }^{65}$.

Es importante resaltar que ya sea que hablemos de limitaciones fácticas o de infracciones fácticas, en ambas circunstancias existe una realidad de hecho, sin sustento jurídico, pero de una u otra forma, tolerada por el Estado.

\subsection{Requisitos de las limitaciones fácticas de los derechos fundamentales}

Ahora bien, con el objeto de identificar con claridad tales limitaciones fácticas, se deben observar cuáles son los requisitos específicos que deben cumplir para que ellas existan como tales.

Los requisitos que propondremos, son los siguientes:

a) Debe existir un derecho fundamental, protegido por el ordenamiento jurídico. Incluso, estimamos que debe existir, además, la pretensión de una o más personas en orden a querer ejercer un determinado derecho esencial, ya que la sola existencia de un enunciado iusfundamental no basta para generar la figura en estudio.

${ }^{65}$ Fermandois (2001), pp. 184-186. 
b) Debe existir una limitación o restricción real al referido derecho, impidiendo a su titular el ejercicio de la facultad, en un caso determinado.

c) En la referida restricción debe faltar alguna de las condiciones para que ésta sea válida. Así, por ejemplo, será fáctica cuando no se cumpla con:

- la condición de carácter competencial, cuando el órgano que impone la restricción no se encuentra constitucionalmente habilitado para hacerlo;

- la condición de carácter internacional, cuando se afecte el derecho internacional;

- la condición de carácter material, cuando aun existiendo habilitación constitucional para restringir un determinado derecho, se le afecta en su esencia, o

- la condición de carácter lógico, que opera al tratarse de una medida restrictiva carente de justificación, o desproporcionada.

d) No obstante lo anterior, la limitación ha de ser impuesta, aceptada o promovida por el Estado, a través de sus órganos. De no existir esta actitud positiva, simplemente existirá una infracción al ordenamiento jurídico, que si es rechazada por la organización estatal, se restablece el imperio del derecho.

Esta aceptación es especialmente notoria y compleja cuando proviene del órgano jurisdiccional, al tratarse de la institución encargada de interpretar y aplicar el Derecho a los casos concretos sometidos a su decisión, y con fuerza de cosa juzgada.

\subsection{De la ilegitimidad de las limitaciones fácticas a los derechos fundamentales}

Asumido lo que son las limitaciones fácticas a los derechos fundamentales, corresponde analizar, por obvio que parezca, el grado de legitimidad o ilegitimidad que sustentan. Revisaremos, pues, el contexto jurídico que circunda esta materia, de modo de establecer si pueden o no validarse estas restricciones.

$\mathrm{Al}$ respecto, debemos recordar dos tipos de normas, que marcarán la pauta para responder dicha interrogante.

Un primer grupo está compuesto por las normas propias del derecho internacional, las cuales podemos clasificar, a su vez, en dos categorías: las de carácter general y aquellas contenidas en tratados internacionales sobre derechos humanos.

Entre las primeras (normas internacionales de carácter general), encontramos los artículos 26 y 27 de la Convención de Viena sobre el Derecho de los Trata$\operatorname{dos}^{66}$ :

${ }^{66}$ Convención de Viena sobre el Derecho de los Tratados, de 1969. 
Art. 26. "Pacta sunt servanda. Todo tratado en vigor obliga a las partes y debe ser cumplido por ellas de buena fe".

Art. 27. "El derecho interno y la observancia de los tratados. Una parte no podrá invocar las disposiciones de su derecho interno como justificación del incumplimiento de un tratado. Esta norma se entenderá sin perjuicio de lo dispuesto en el artículo 46".

En tanto, respecto de la segunda categoría de normas (normas internacionales contenidas en tratados sobre derechos humanos), podemos destacar las siguientes:

Convención Americana sobre Derechos Humanos: Art. 1.1.

"Los Estados Partes en esta Convención se comprometen a respetar los derechos y libertades reconocidos en ella y a garantizar su libre y pleno ejercicio a toda persona que esté sujeta a su jurisdicción, sin discriminación alguna por motivos de raza, color, sexo, idioma, religión, opiniones politicas o de cualquier otra indole, origen nacional o social, posición económica, nacimiento o cualquier otra condición social".

Pacto Internacional de Derechos Civiles y Políticos: Art. 2.1.

"Cada uno de los Estados Partes en el presente Pacto se compromete a respetar y garantizar a todos los individuos que se encuentren en su territorio y estén sujetos a su jurisdicción los derechos reconocidos en el presente Pacto, sin distinción alguna de raza, color, sexo, idioma, religión, opinión politica o de otra indole, origen nacional o social, posición económica, nacimiento o cualquier otra condición social".

Pacto Internacional de Derechos Económicos, Sociales y Culturales:

Art. 2.2. "Los Estados Partes en el presente Pacto se comprometen a garantizar el ejercicio de los derechos que en él se enuncian, sin discriminación alguna por motivos de raza, color, sexo, idioma, religión, opinión politica o de otra indole, origen nacional o social, posición económica, nacimiento o cualquier otra condición social".

A la luz de todas estas disposiciones, queda en absoluta evidencia que los Estados se encuentran siempre obligados a cumplir sus compromisos internacionales y que en el ámbito de los Derechos Humanos ello implica no sólo la obligación positiva de respetarlos y promoverlos, sino que además, el deber negativo de no violarlos, ni de fijar o aceptar limitaciones que no sean toleradas por el derecho internacional.

Desde esta perspectiva, la figura de las llamadas "limitaciones fácticas de los derechos fundamentales", termina siendo una flagrante falta a las obligaciones internacionales, transformando al Estado infractor en sujeto pasible de responsabilidad internacional. 
$\mathrm{Al}$ respecto, la Corte Interamericana ha establecido que el no cumplimiento de las normas internacionales sobre restricción de derechos, acarrea responsabilidad estatal. Así, por ejemplo, en el caso Ricardo Canese contra Paraguay señaló: "la Corte considera que el Estado violó el derecho a la libertad de pensamiento y de expresión consagrado en el artículo 13 de la Convención Americana, en relación con el artículo 1.1. de dicho tratado, en perjuicio del señor Ricardo Canese, dado que las restricciones de este derecho impuestas a éste durante aproximadamente ocho años excedieron el marco contenido en dicho artículo ${ }^{67}$ ".

Un segundo grupo de normas son aquéllas de origen constitucional, que se refieren directa o indirectamente a estas materias, y que fijan un marco suficiente para sostener que el reconocimiento de las limitaciones fácticas de los derechos fundamentales es, por esencia, inconstitucional.

Como primera observación, podemos sostener que fijar o aceptar dichas restricciones por parte de los órganos del Estado, no atiende al principio de servicialidad del Estado, consagrado en el inciso cuarto del art. $1^{\circ}$ de la Carta Fundamental, por el cual éstos deben estar, ante todo, al servicio de la persona humana, y no de otro tipo de consideraciones.

Esa conducta tampoco es respetuosa con el principio de la supremacía constitucional establecido en el art. $6^{\circ}$ de nuestro Código Político, por cuanto, se soportan restricciones en casos o condiciones no previstas por la Carta Fundamental, apartándose de su texto, esencialmente de carácter imperativo.

Es, a su vez, incompatible con el principio de juridicidad expuesto en el art. $7^{\mathrm{o}}$ de la Constitución Política ${ }^{68}$, ya que el organismo que acepte las limitaciones fácticas está actuando fuera del contexto normativo que regula la situación específica a la que se refiere. Por lo mismo, los actos que incurran en este vicio, adolecen de Nulidad de Derecho Público.

Nos parece que establecer o aceptar una restricción a derechos que, a sabiendas no es lícita, tampoco es una conducta honesta, por lo que se atenta en contra del

\footnotetext{
${ }^{67}$ Corte Interamericana de Derechos Humanos, "Ricardo Canese contra Paraguay” (2004), párrafo 108.

${ }^{68}$ Constitución Política de la República:

Art. 7o CPR: "Los órganos del Estado actúan válidamente previa investidura regular de sus integrantes, dentro de su competencia y en la forma que prescriba la ley.

Ninguna magistratura, ninguna persona ni grupo de personas pueden atribuirse, ni aun a pretexto de circunstancias extraordinarias, otra autoridad o derechos que los que expresamente se les hayan conferido en virtud de la Constitución o las leyes.

Todo acto en contravención a este artículo es nulo y originará las responsabilidades y sanciones que la ley señale".
} 
principio de probidad consagrado en el art. $8^{\circ}$ inciso primero de nuestra Carta Magna ${ }^{69}$.

Y, naturalmente, se afecta el contenido esencial de los derechos y, por lo tanto, se viola la garantía del numeral 26 del art. 19 de la CPR.

Por las razones expuestas, y en virtud de las normas reseñadas, el establecimiento, aceptación y validación de limitaciones diferentes a las aceptadas por la Carta Fundamental o que, por cualquier motivo, no cumplan con las condiciones de validez ya expuestas, es por sí sola una conducta extraña al ordenamiento jurídico, atenta contra el derecho internacional de los derechos humanos, y por cierto es, evidentemente, inconstitucional.

\subsection{Algunos casos de limitaciones fácticas}

Luego de haber analizado la noción de limitaciones fácticas a los derechos fundamentales, parece conveniente comprobar la existencia de las mismas en casos concretos. Del análisis de cierta jurisprudencia, podemos constatar que algunas de ellas pueden provenir, por ejemplo, de restricciones presupuestarias del Fisco, en relación con derechos que no son de los llamados prestacionales. Así ha ocurrido, por ejemplo, en la década de los ochenta, con enfermos renales necesitados de tratamientos de diálisis, o en los noventa con algunos enfermos portadores de VIH, casos que ya abordáramos en una ocasión anterior. ${ }^{70}$

A estas restricciones, que no son admisibles, bajo los parámetros anteriormente analizados, se unen aquellas que implican el reconocimiento de facultades de órganos de la Administración Pública.

En efecto, los Tribunales Superiores de Justicia, en distintos casos, han aceptado que los órganos pertenecientes a la Administración Pública provoquen determinadas afectaciones a las garantías consagradas en particular, en el artículo 19 No 1 de nuestro Código Político ${ }^{71}$, cuando dichas conductas forman parte del ejercicio de facultades discrecionales de aquellas entidades del Estado.

${ }^{69}$ Constitución Política de la República:

Art. $8^{\circ} \mathrm{CPR}$, inciso primero: "El ejercicio de las funciones públicas obliga a sus titulares a dar estricto cumplimiento al principio de probidad en todas sus actuaciones".

${ }^{70}$ Sobre el particular, ver Tórtora Aravena, Hugo, op. cit., pp. 235-242.

${ }^{71}$ Art 19. "La Constitución asegura a todas las personas:

$1^{\circ}$. El derecho a la vida y a la integridad fisica y psíquica de la persona.

La ley protege la vida del que está por nacer.

La pena de muerte sólo podrá establecerse por delito contemplado en ley aprobada con quórum calificado.

Se prohibe la aplicación de todo apremio ilegítimo". 
Citaremos, a manera de ejemplo, un recurso incoado en contra del Director Nacional de Gendarmería, del Director Regional de Gendarmería de la Región Metropolitana, y del Jefe de Unidad del Centro de Cumplimiento Penal Colina II, por parte de una mujer, pareja de un recluso cuya salud mental se ha ido deteriorando progresivamente. El motivo de este daño sería, según la actora, la imposición de una sanción disciplinaria en su contra ${ }^{72}$, la cual ha generado en el reo, una vulneración a las garantías del artículo 19 números 1, 2, 3, 7 letras b y d, y 9 de la Constitución, por lo cual solicita a la Corte de Apelaciones de Santiago que ordene que el imputado sea puesto en manos de un especialista, y la sanción impuesta anulada o que sea sancionado en forma más humanitaria. La Corte de Apelaciones capitalina acoge la mencionada acción ${ }^{73}$, dejando constancia que "si bien el régimen penitenciario faculta la adopción de medidas dirigidas a garantizar la vida e integridad fisica o psíquica de las personas y el orden y seguridad en el recinto, y que estas mismas deben adoptarse en razón de la reincidencia, tipo de delito, de reiteradas infracciones al régimen interno u otros que el reglamento señala, no es menos cierto que en ningún caso estas medidas pueden restringir los derechos de los internos de forma tal que la aplicación implique que el carácter extraordinario de ellas se transforme en un régimen ordinario como en la práctica ha sucedido, si se razona que los hechos se originaron el 18 de mayo pasado y de los antecedentes adjuntos no se desprende que se haya establecido una fecha determinada para el término de la medida, lo cual permite concluir que ella es excesiva, atendido que en la práctica el régimen de privación de libertad extraordinaria que sufre el rematado, se ha transformado en permanente, circunstancia que sin duda afecta la salud fisica y mental del interno" (Considerando $3^{\circ}$ ). Vale decir, aun reconociendo la facultad que tiene Gendarmería para decretar sanciones o medidas disciplinarias, bajo ninguna circunstancia ellas pueden lesionar la dignidad y los derechos más básicos de las personas privadas de libertad.

Sin embargo, la Corte Suprema, en segunda instancia, revoca la decisión del Tribunal a quo, no sólo porque efectivamente el condenado tenía un mal comportamiento que ameritaba una drástica sanción, sino además, porque la determinación de Gendarmería se encontraba amparada por facultades legalmente establecidas, las cuales no discutió ni reprochó. Efectivamente, el Máximo Tribunal expresó que "constituye una facultad de la Dirección de Gendarmería la de disponer el traslado de internos en caso de que éstos lleven a cabo actos de indisciplina, como ocurre

\footnotetext{
${ }^{72}$ Lamentablemente, el fallo analizado no deja constancia con exactitud de la medida disciplinaria adoptada en contra del reo.

${ }^{73}$ Corte de Apelaciones de Santiago, "Muñoz Silva, Teresa del Carmen con Director Nacional de Gendarmería y otros" (2003).
} 
en la especie", y agregó que "tan sólo a mayor abundamiento, hay que mencionar que las facultades de la autoridad recurrida para actuar como se le reprocha y para mantener un régimen de disciplina acorde con la calidad de los internos, derivan del Decreto Ley $N^{o} 2.859$, especialmente sus artículos $1^{\circ}, 2^{\circ}, 3^{\circ}$ y $6^{\circ}$, que constituye la Ley Orgánica del Servicio y en el Decreto Supremo $N^{o} 518$, que contiene el referido Reglamento, particularmente sus artículos 1ㅇ, 24, 25, 26 y 28" (Considerandos $5^{\circ}$ y $\left.6^{\circ}\right)$. Lo que es, según nuestra opinión, más delicado aun, la Suprema Corte ni siquiera analizó los derechos aparentemente vulnerados del ofendido, por lo que no realizó juicio alguno de proporcionalidad. O sea, no revisó la posibilidad que la conducta fuera irracional, desproporcionada o arbitraria, faltando gravemente a los deberes constitucionales y a su función conservadora. Lo anterior, queda de manifiesto en el considerando 90 de la sentencia en análisis, que reza: "en cuanto a las garantías constitucionales estimadas vulneradas, no resulta necesario referirse a las mismas, habida cuenta de la no existencia de un acto arbitrario o ilegal, como se indico".

En otros casos, los Tribunales han tolerado que los Tribunales limiten, en casos no previstos por la Constitución Política, derechos fundamentales de terceros. En estos términos, recordemos que es un principio básico que nada se logra con intentar proteger la vida del ser que está por nacer, si no se protege la vida ni la integridad física y psíquica de la mujer embarazada.

En el caso de mujeres en estado de gravidez que se encuentran desempeñando trabajos remunerados, la situación se torna en especial delicada, ya que muchas veces las funciones que cumple en su lugar de trabajo pueden ser incompatibles con el debido cuidado del hijo que se gesta. Por este motivo, el artículo $202 \mathrm{del}$ Código del Trabajo chileno establece el derecho de la trabajadora a ser trasladada a otra función, si la que ejerce actualmente resultare perjudicial para su salud ${ }^{74}$. A su vez, se establece por ley el fuero maternal y los descansos pre y posnatales que también tienen por objeto proteger a la mujer que se encuentra en condiciones de preñez, así como aquella que ha sido madre recientemente ${ }^{75}$. Por su parte, por expresa disposición del Código del Trabajo, las normas en él contenidas sobre

\footnotetext{
${ }^{74}$ Código del Trabajo: "Art. 202. Durante el periodo de embarazo, la trabajadora que esté ocupada habitualmente en trabajos considerados por la autoridad como perjudiciales para su salud, deberá ser trasladada, sin reducción de sus remuneraciones, a otro trabajo que no sea perjudicial para su estado.

Para estos efectos se entenderá, especialmente, como perjudicial para la salud todo trabajo que: (a) obligue a levantar, arrastrar o empujar grandes pesos; (b) exija un esfuerzo fisico, incluido el hecho de permanecer de pie largo tiempo; (c) se ejecute en horario nocturno; (d) se realice en horas extraordinarias de trabajo, y (e) la autoridad competente declare inconveniente para el estado de gravidez".

${ }^{75}$ Artículos 201 y 195 del Código del Trabajo.
} 
protección a la maternidad también se extenderán, extraordinariamente, a los organismos públicos ${ }^{76}$.

Por todas estas consideraciones y normas aplicables, no deja de llamar la atención un caso suscitado en Atacama. Allí una secretaria que trabajaba en la Compañía Minera Tres Cruces, más específicamente en el Campamento Marte, ubicado a $220 \mathrm{Km}$ de aquella ciudad, a $3.500 \mathrm{~m}$ de altura sobre el nivel del mar y en una zona de condiciones climáticas muy duras, solicita a sus empleadores ser trasladada a las oficinas de Copiapó, atendido a que se encontraba embarazada de gemelos. Además, la empresa no le había asegurado todas las garantías para poder amamantar a sus hijos, una vez que éstos nacieran.

La Corte estima que la situación de embarazo en la que se encuentra la recurrente "es ajena a la empresa, cuyos representantes no han realizado ningún acto ni incurrido en omisión alguna que haya privado, perturbado o amenazado [el derecho a la vida e integridad física y psíquica de la recurrente e hijos]". El Tribunal agrega que "los inconvenientes que puedan ocasionarse a la recurrente y sus hijos, por las condiciones del lugar donde ella debe prestar sus funciones, en el ejercicio de los derechos contemplados en su favor, deberán ser resueltos de acuerdo a la normativa y por las autoridades que la legislación laboral contemple, en cada caso ${ }^{77}$ ". Como hemos visto, la Corte tampoco revisa una eventual arbitrariedad del empleador, ni ordena medida alguna que busque la debida protección de los gemelos en formación, sino que derechamente procede a rechazar el recurso por las razones antes expuestas, como si un particular tuviera atribuciones para restringir el derecho a la vida de otros, o al menos, la protección de la vida del ser que está por nacer.

Así las cosas, se puede apreciar que en este caso como en otros, los Tribunales se han valido de las normas laborales y administrativas para justificar las infracciones a las leyes sobre protección a la maternidad, las cuales, por lo demás, tienen el mismo carácter. Nos parece que ante un eventual choque entre dos disposiciones

\footnotetext{
${ }^{76}$ Código del Trabajo: "Art. 194. La protección a la maternidad se regirá por las disposiciones del presente título y quedan sujetos a ellas los servicios de la administración pública, los servicios semifiscales, de administración autónoma, de las municipalidades y todos los servicios y establecimientos, cooperativas o empresas industriales, extractivas, agricolas o comerciales, sean de propiedad fiscal, semifiscal, de administración autónoma o independiente, municipal o particular o perteneciente a una corporación de derecho público o privado.

Las disposiciones anteriores comprenden las sucursales o dependencias de los establecimientos, empresas o servicios indicados. Estas disposiciones beneficiarán a todas las trabajadoras que dependan de cualquier empleador, comprendidas aquellas que trabajan en su domicilio y, en general, a todas las mujeres que estén acogidas a algún sistema previsional. Ningún empleador podrá condicionar la contratación de trabajadoras, su permanencia o renovación de contrato, o la promoción o movilidad en su empleo, a la ausencia o existencia de embarazo, ni exigir para dichos fines certificado o examen alguno para verificar si se encuentra o no en estado de gravidez".

77 Corte de Apelaciones de Copiapó, “Oviedo Ángel con Compañia Minera Tres Cruces” (2001).
} 
legales, deberá preferirse aquella que mejor se condiga con la Constitución en general, y con las garantías fundamentales en particular.

\section{CONClusiones}

1. Las limitaciones a los derechos fundamentales son elementos perfectamente compatibles con la debida protección del ser humano, son herramientas aptas para la defensa de la persona.

2. Estas limitaciones pueden ser ordinarias o extraordinarias, según si operen en todo momento, o sólo bajo estados de excepción constitucional. También pueden provenir del respeto por los derechos fundamentales de los demás sujetos, o de condiciones materiales o físicas (en el caso de derechos prestacionales), o bien soberanamente consagradas en el ordenamiento jurídico positivo. Estas últimas, finalmente deben siempre tener sustento constitucional, por lo que hemos distinguido entre limitaciones directamente constitucionales e indirectamente constitucionales.

3. Para que las limitaciones a los derechos fundamentales sean legítimas deben cumplir con diversas condiciones. En primer lugar, deben ser generadas por quien tenga las competencias para ello, cuestión que debe quedar resuelta en el plano constitucional. En segundo término, deben cumplir los estándares jurídicos que establece el derecho internacional de los derechos humanos, el cual fija reglas claras en este punto. Por último, las limitaciones deben respetar el contenido esencial del derecho, así como ser justificadas y proporcionales.

4. No obstante lo anterior, es posible descubrir en la jurisprudencia nacional, casos donde los Tribunales han aceptado restricciones a derechos fundamentales que no cumplen con uno o más de los requisitos antes planteados. Si los órganos judiciales no hubieran prestado su anuencia, estos casos no pasarían a ser más que meras afectaciones o vulneraciones de derechos. Pero del momento que el orden institucional las acepta, se convierten en verdaderas limitaciones fácticas a los derechos, concepto que hemos desarrollado en este trabajo.

\section{Bibliografía Consultada}

AleXY, Robert (2002): Teoría de los Derechos Fundamentales, Tercera Reimpresión (Madrid, Centro de Estudios Políticos y Constitucionales). 607 págs.

Arango Rivadeneira, Rodolfo (2005): El concepto de derechos sociales fundamentales, (Bogotá, Legis Editores). 380 págs.

Cançado Trindade, Antônio (2006): El Derecho Internacional de los Derechos Humanos en el Siglo XXI, Segunda Edición (Santiago de Chile, Editorial Jurídica). 560 págs. 
Cea Egaña, José Luis (2002): Derecho Constitucional Chileno, Tomo II (Santiago de Chile, Ediciones Universidad Católica de Chile). 737 págs.

Fermandois Vöhringer, Arturo (2001): Derecho Constitucional Económico, Tomo I (Santiago de Chile, Ediciones Universidad Católica de Chile). 333 págs.

Fernández González, Miguel Ángel (2002): "Aspectos Constitucionales de la nueva ley de OPAS", en Revista Chilena del Derecho (Santiago de Chile, Volumen 29, No 3, Facultad de Derecho, Pontificia Universidad Católica de Chile). Págs. 685-697.

HäBerle, Peter (2003): La Garantía del Contenido Esencial de los Derechos Fundamentales, Madrid, Editorial Dykinson. 312 págs.

LORENZO RodríGUeZ-Armas, Magdalena (1996): Análisis del contenido esencial de los derechos fundamentales enunciados en el art. 53.1. de la Constitución Española. (Granada, Editorial COMARES). 252 págs.

Nogueira Alcalá, Humberto (2008): Derechos Fundamentales y Garantías Constitucionales (Santiago de Chile, Editorial Librotecnia, Segunda edición corregida). Tomo I, 748 págs.

Pereira Menaut, Antonio Carlos (2006): Teoría Constitucional, Segunda Edición (Santiago de Chile, Editorial LexisNexis). 526 págs.

Prieto Sanchís, Luis (2003): Justicia Constitucional y Derechos Fundamentales. (Madrid, Editorial Trotta). 308 págs.

Quinzio Figueiredo, Jorge Mario (2006): Tratado de Derecho Constitucional, Tomo I, Segunda Edición (Santiago de Chile, Editorial LexisNexis). 328 págs.

Ríos Álvarez, Lautaro (2005): "Los Estados de Excepción Constitucionales en una perspectiva humanista", en A.A.V.V. La Constitución Reformada de 2005 (Santiago de Chile, Editorial Librotecnia). Págs. 319-344.

Risso Ferrand, Martín (2008): "Algunas garantías básicas de los Derechos Humanos" (Montevideo, Fundación de la Cultura Universitaria). 184 págs.

Tórtora Aravena, Hugo (2005): "El Derecho a la Vida en la Jurisprudencia

Constitucional: aproximación al análisis de su delimitación, limitación y configuración”, en Revista Estudios Constitucionales del Centro de Estudios Constitucionales de la Universidad de Talca, Año 3, No 2 (Santiago de Chile, Editorial Librotecnia). Págs. 199-247.

\section{Normas Jurídicas Citadas}

Constitución Política de la República de Chile, Decreto Supremo del Ministerio Secretaría General de la Presidencia, $N^{\circ} 100$, que fija el texto refundido, 
coordinado y sistematizado de la Constitución Política de la República de Chile, publicado en el Diario Oficial el 22 de septiembre de 2005, y sus modificaciones posteriores.

Convención de Viena sobre el Derecho de los Tratados, del 23 de mayo de 1969, su instrumento de ratificación depositado el 9 de abril de 1981 y publicada en el Diario Oficial, el 22 de junio del mismo año.

Pacto Internacional de Derechos Económicos, Sociales y Culturales, del 19 de diciembre de 1966, el instrumento de ratificación depositado el 10 de febrero de 1972, y publicado en el Diario Oficial el 27 de mayo de 1989.

Pacto Internacional de Derechos Civiles y Políticos, fue firmado el 16 de diciembre de 1966, su instrumento de ratificación depositado el 10 de febrero de 1972, y publicado en el Diario Oficial el 29 de abril de 1989.

Convención Americana sobre Derechos Humanos, de fecha 22 de noviembre de 1969, su instrumento de ratificación fue depositado el día 21 de agosto de 1990, y publicada en el Diario Oficial el 5 de enero de 1991.

Ley N ${ }^{\circ} 18.415$, Orgánica Constitucional sobre Estados de Excepción Constitucional, publicada en el Diario oficial el 14 de junio de 1985.

\section{JURISPRUDENCIA CITADA}

\section{Corte Interamericana de Derechos Humanos}

Zambrano Vélez y otros vs. Ecuador: Corte Interamericana de Derechos Humanos, 4 de julio de 2007 (caso contencioso), disponible en: http://www.corteidh. or.cr/docs/casos/articulos/seriec_166_esp1.pdf, consultado el 30 de marzo de 2010.

Ricardo Canese contra Paraguay. Corte Interamericana de Derechos Humanos, Sentencia del día 31 de agosto de 2004, Serie C, número 11, párrafo 108, disponible en: http://www.corteidh.or.cr/docs/casos/articulos/seriec_111_esp. pdf, consultado el 30 de marzo de 2010.

"La expresión 'leyes' en el artículo 30 de la Convención Americana sobre Derechos Humanos": Corte Interamericana de Derechos Humanos del 9 de mayo de 1988, (Opinión Consultiva OC-6/86), disponible en: http://www.corteidh.or.cr/ docs/opiniones/seriea_06_esp.pdf, consultado el 30 de marzo de 2010.

"El hábeas corpus bajo suspensión de garantías. Corte Interamericana de Derechos Humanos, 30 de enero de 1987, Serie A No 8, párr. 21 (Opinión Consultiva OC-8/87), disponible en: www.corteidh.or.cr/docs/opiniones/seriea_08_esp. doc, consultado el 30 de marzo de 2010. 


\section{Tribunal Constitucional chileno}

Control de Constitucionalidad de la Ley Orgánica Constitucional sobre Partidos Políticos, Tribunal Constitucional chileno: Sentencia del 24 de febrero de 1987, Rol No 43, disponible en www.tribunalconstitucional.cl, consultado el 30 de marzo de 2010.

Caso "Publicidad Caminera I", Tribunal Constitucional chileno, Sentencia del 21 de abril de 1992, Rol No 146, disponible en www.tribunalconstitucional.cl, consultado el 30 de marzo de 2010.

Caso "Publicidad Caminera II", Tribunal Constitucional chileno: Sentencia del 6 de abril de 1993, Rol No 167, disponible en www.tribunalconstitucional.cl, consultado el 30 de marzo de 2010.

Control de constitucionalidad respecto del proyecto de ley que moderniza el Servicio Nacional de Aduanas, Tribunal Constitucional chileno: Sentencia del 22 de octubre de 1996, Rol No 248, disponible en www.tribunalconstitucional.cl, consultado el 30 de marzo de 2010.

Requerimiento de inaplicabilidad presentado por Empresa Eléctrica Panguipulli S.A. respecto del artículo $3^{\circ}$ transitorio de la Ley $N^{o} 19.940$, en la causa caratulada "HQI Transelec S.A. con Empresa Eléctrica Panguipulli S.A." que se sigue ante la Corte de Apelaciones de Santiago, Tribunal Constitucional chileno: Sentencia del 6 de marzo de 2007, Rol No 505, disponible en www.tribunalconstitucional. cl, consultado el 30 de marzo de 2010.

\section{Tribunales Ordinarios (acciones de protección)}

“Oviedo Ángel con Compañía Minera Tres Cruces”, Sentencia de la Corte de Apelaciones de Copiapó, Sentencia definitiva Rol No 3.194, confirmada por la Corte Suprema el 12 de marzo del mismo año, en Revista de Derecho y Jurisprudencia, Tomo LXXXVIII, No 3, año 1991, págs. 98-100.

"Muñoz Silva, Teresa del Carmen con Director Nacional de Gendarmería y otros", Corte de Apelaciones de Santiago, Sentencia definitiva de fecha 29 de agosto de 2003, caso Rol No 4.720-2003 (recurso de protección), revocada por la Corte Suprema el 7 de octubre de 2003 Rol No 3.920-2003, en Revista de Derecho y Jurisprudencia Tomo C, № 2, año 2003, págs. 124-127. 